\title{
What do students value in Built Environment education?
}

\section{Dr Andrea Frank, CEBE Subject Co-ordinator for Planning; Lecturer}

School of City and Regional Planning, Cardiff University

Email: FrankA@Cardiff.ac.uk

\begin{abstract}
In order to enhance the student learning experience, students' opinions and values need to be analysed and understood. This paper provides a review and general analysis of how students learn and what teaching approaches and learning opportunities they consider most valuable and essential to their future careers in the Built Environment professions. Findings are based on statements and reflections from five student essays on the subject.
\end{abstract}

Keywords: Student Experience, Teaching Quality Enhancement, Best Practice, Curriculum Design 
According to a survey by McLernon and Hughes (2005, this issue), students go to university to obtain a degree which will enhance their employment opportunities. Moreover, students' choice of a University has little to do with an institution's research capability or quality - although a universities' (research) reputation is seen as a factor that can increase the value of a degree. Consequently, what matters to an overwhelming proportion of university students is teaching and learning: learning about a subject, preparation for the workplace and the conveyance of personal and key skills.

To gain a deeper insight into these issues, the Centre for Education in the Built Environment ran a nation-wide student competition in the first few months of 2005 to elicit what motivates undergraduates in Architecture, Planning, Surveying and related subjects to learn and what helps them learn more effectively. Students were asked to submit a short essay expressing their personal opinions and experiences on "What makes the best learning experience for a Built Environment student?" In particular the essays were to

- $\quad$ Highlight the attributes which make the best learning experience for a built environment student;

- $\quad$ Define and differentiate what is understood by 'good learning experiences';

- Include examples of good and/or innovative teaching, learning and assessment methods;

- $\quad$ Give the reader an overview of the factors that comprise 'good learning experiences'.

Entries were received from surveying, construction and architecture students. In many respects the answers are not at all unexpected and some common threads emerge. Frequently, positive learning experiences recounted by the students relate to hands-on practical sessions, customary in almost all built environment curricula and designed to prepare students for the workplace. For educators, this is re-assuring reading and it represents an incentive to maintain and perhaps increase the amount of practiceorientated teaching despite the fact that it can be a resource intensive and time consuming approach to teaching.

There were, however, some unexpected aspects, opinions and much valued experiences which make for interesting reading. It is those experiences that provide food for thought and help us reflect on how to potentially improve the student learning experiences in our programmes once basic quality levels have been reached.

Generalising from these novel ideas or implementing these 'valued' experiences without further research and reflection will be difficult and is not necessarily advocated. The good learning experiences are after all derived from a very small, self-selected sample of students. Moreover, students' individual experiences differ even in the same university and programme due to their differing backgrounds, preferred learning styles, prior experiences and knowledge, all of which impact on what an individual values in their learning. Consequently, a particular good learning experience may suit some 
students but not others and improving students' experiences may involve the development of individual and personalised learning paths.

Excerpts from the five finalist competition essays are used here to illustrate what these particular students value most in their courses and learning. In sum, five factors that comprise good learning experiences can be drawn from the students' writing.

Thematically they can be grouped into

- hands-on, practice-relevant education,

- $\quad$ seeing things with your own eyes,

- $\quad$ teacher enthusiasm and experience, (experiential learning),

- team-working, and

- tactile, emotional experiences.

\section{Hands-on, Practice-relevant education}

In one form or another, most student entries make reference to the special value of practice-relevant, hands-on learning - particularly in the Built Environment professions where things are decidedly tangible and real. An overseas student highlights the professional skills module with practical sessions on IT and presentation skills as one of her most valued and enjoyable learning experiences in her course. Interestingly, the student acknowledges that this valuation is retrospective. Apparently at the time the learning experience itself was not quite that pleasant. By contrast, the practice-based education that another student cherishes stems from a placement. The experience is valued not only for the learning but also the contacts she was able to make during this time, which she found useful for her dissertation work and which will probably help her in finding a job after her degree:

However, in my opinion, the most valuable learning experience that can be gained by a built environment student is an industry placement. Being able to apply theoretical knowledge within the work place is crucial in enabling a student to gain confidence in their own ability. A work placement opportunity is currently integrated during the third year of my course (...) During this time I have forged vital contacts and resources that may be utilised for my forthcoming dissertation. If, however, an academic institution does not provide the opportunity during term time then students should be actively encouraged to ascertain this during the summer months. (Fiona Irving)

While most students value practical experience, the type of practical experience varies. While Fiona enjoyed the industry experience, another student suggests that it is vital for those working within the Built environment to acquire 'interaction skills'. Defined broadly this means that students need to come to terms with the complexity of their (potential) clients' needs and opinions. He claims that such interaction cannot be taught in a traditional sense but needs to be learned through experience and students own initiative. He therefore suggests: 
... placements, that put the students in temporary positions within community work of an indirect source, so that they can be shown how they can earn such lessons of communication. (Jonathan Pugh)

\section{Seeing things with your own eyes (experiential learning)}

Considering that we are constantly surrounded by buildings and infrastructure, it is surprisingly difficult to witness the actual process of construction that lead to a building's existence. Constructions sites are often hidden behind high fences and the general public is kept in safe distance from most construction sites. One of the students implied that some aspects in built environment education are difficult to visualise from a mere verbal account in a classroom and are better understood by seeing them first hand:

I found this whilst undertaking a construction module as the processes being described were of a large scale and had never been previously viewed [by me]. Therefore, being able to visit sites whereby certain processes may be undertaken is both extremely useful and enjoyable. (Fiona Irving)

Realising that it is not always possible or feasible to organise site visits with large groups of students another student suggests that images and graphic representations can serve as effective aids which certainly enhanced her learning experience:

For me visual aids are always welcome. Video recordings about House construction have been more than useful. Our tutors bring in materials such as roofing tiles, wood, connector bolts, bricks and blocks. (Yvette Regis)

\section{Teacher Enthusiasm and Experience}

It is without doubt that a passionate and enthusiastic teacher makes learning more fun in any subject. Not surprisingly, a number of students expressed that they learn better when the topic is delivered imaginatively, as well as enthusiastically. We probably have experienced the difference as pupils ourselves and this appears to be perpetuated at the advanced levels of education.

Yet, for students on built environment courses there appears to be an additional, albeit related, aspect to teacher enthusiasm: personal experience. The underlying assumption here is that engagement and personal experience in a subject contributes significantly to a person's ability to teach and explain a subject in a convincing manner. One contributor offers perhaps the most poignant statement reasoning that teaching needs to inspire and explain comprehensively why things are done in a certain way. The key element in terms of good learning experience is how knowledge is passed on:

So how does this translate to my learning experience? How are the whys passed on? To simply read aloud from the dummies instruction book would not be enlightening as to the whys. And this highlights the part I value most about my learning experience at my University. Not one of my tutors simply 
regurgitates textbooks. They were all there themselves. They stood in the mud and, it being the North West, the perpetual wind and rain. They watched the works progress, frequently under their own personal instruction, and they thought out the solutions when, as it happens, it all went a bit wrong. They can bring personal examples to almost any aspect of construction and bring the subject to life. No classroom question goes without immediate answer or explanation, the successes and the failures of their own experience are passed on in vivid colour. They can explain why they went about something in a certain way, why certain things happened as a result, and why a certain solution was reached - and we can take these whys away from the lesson with us. (Felicity Rawlinson)

So, second to experiencing something yourself - is a sort of 'eye-witness' account of how things in architecture, construction etc are done. Although deeper learning may be achieved by doing something yourself, this is not always realistic, nor safe. Enthusiastic eye-witness reports, perhaps supported with visual materials can apparently substitute well for a personal and first hand experience.

\section{Working in Teams}

Another prominent theme in the students' essays was working in teams. There is a clear understanding that "Construction is done in teams." Hence, the group work and practice to work in teams is valued by students - albeit group work can have disadvantages as well as benefits. In particular, a construction management student expressed it as follows:

... another keystone of the learning experience (...) that gives an excellent grounding for students is teamwork. It is a rare construction project that is completed entirely by a single person. You are pretty much limited to something the size of a shed, but even then someone else is needed to hold the walls in place whilst you hammer away. The industry relies on hundreds of different trades to create a completed structure and teamwork is essential. It is also a key part of the programme (...) and assessment is geared to team performance. On a construction site you have many aspects of work ongoing, and you can bet that someone isn't going to make good on their promises. A late section to a presentation equates to late roof trusses, knocking your PowerPoint slide show or your roofing contractor into the following week. And delays cost marks or money. Having to manage scenarios like this at University teaches a valuable lesson in people management for an unreliable world. (Felicity Rawlinson)

This statement is mirrored by Yvette, who believes that students need to learn to work as teams not only because sharing ideas increases their knowledge base and widens their experiences but also because "it is important for our future career." There is a 
realisation that group work can be managed by choosing one's groups very carefully to help guarantee good results.

\section{Tactile and Emotional Experiences}

It is an accepted fact that many built environment professions are visually orientated. However, the submission of an architecture student suggests that experiences that bridge the gap between drawing and making are indispensable to architecture education (and probably the whole gamut of education in the Built environment). The student is wary of designers and architects working only through the medium of computer models and digital drawing software:

Architects merely drawing lines become dangerously detached from the physicality of what they are producing. ... We live in a tactile world, not just a visual bubble. (Ros Scott)

Ros further suggests that traditional drawing rather than drawing and designing using computer software, is a tangible, tactile experience that is vital to the profession. The act of "putting the pen to paper," holding a pen, drawing different lines manually, provides a different way of expressing oneself. Secondly, she suggests that any budding architects and other space-makers need to understand construction and material. Again it is the physical contact with and handling of wood, concrete brick, steel, and glass etc that is identified as a key experience:

This cannot be learnt from the drawing board, but from the use of the materials themselves. Touch, weigh, and feel. Then cut, grind, sand, drill, mould. Work with them. (Ros Scott)

The student suggests that these kinds of physical experiences are not offered in the university context (any more) and she advises her peers to take charge of their own education. She advocates that fellow students should work for a small office where there is still manual drawing work for a month or two as well as seek out work on a building site for a carpenter, or renovating a flat or house. She also suggests students should use any opportunity to experiment and simulate building processes with real materials when model building for example.

Similarly, Jonathan suggests that learning outside the university, the classroom and even outside the profession is relevant because it addresses the "fundamental 'interaction' based void that exist within the build environment education system." $\mathrm{He}$ believes that students in the BE professions need to understand the people for whom they create and build. This can be a humbling experience - as professional experience and knowledge may not be readily accepted and learning to listen and gain the trust of others is part of the interaction skill that he finds so important. 


\section{Lessons from Students' Learning Experiences?}

On one hand, the student accounts are exceedingly heartening as many BE courses already provide experiences that students' value highly: guest lectures, professional skills training sessions, group projects and assessed industry placements for example. Here is a justification for diverse learning opportunities and for maintaining resource intensive teaching approaches such as study visits and practicals.

On the other hand, it may be somewhat worrying that Built Environment students appear to see little value in theory, ethics or other abstract topics in respect to their disciplines. Practically all factors (except teacher attitudes) that students identified as motivating and enhancing their learning experience are practice orientated, hands-on, or experiential. However, there may be lessons to be learned from what is omitted in the student experience. Is it that student learning experiences in theory or ethics are non-existent, or more likely rather negatively perceived? Turning theory or ethics into relevant and interesting classroom material has been recognised as a challenge by Built Environment educators for decades (e.g., d'Anjou, 2004; Forester, 2004; Frank, 2002; Kaufman, 1993) and in 2005 the Association of European Planning schools (AESOP) selected teaching theory as theme for its Excellence in Teaching prize. This concern of the educators together with the lack of students' accounts can be interpreted in two ways. For one, perhaps we have not yet found a consistently good model for linking theory with practice or (and this is not the first time this is suggested) theory is indeed unimportant to BE education and educators unnecessarily cling to a topic of little value.

Suggestions for improvements can also be derived from those experiences that students feel are crucial to an education in the Built Environment but are not (sufficiently) supported and provided for by university courses at present - the tactile, emotional experiences identified as valuable learning experiences by a subset of the students. To be fair, as for drawing, there is a fine balance between becoming computer literate (as this helps employability) and the perfecting of traditional drawing and drafting skills (which takes a long time). In today's day and age where universities are under significant pressure to churn out students with the skills that employers have identified in as short a time as possible, there are limits to what can be offered within the curriculum. For better or worse in a university system for the masses, it seems simply unfeasible to offer a Bauhaus style education (Bayer, 1975) - although some Australian Universities have attempted to adopt elements of the holistic Bauhaus teaching style for IT training and education (Lynch et al. 2002). Meanwhile, Ros' advice to her peers to grasp opportunities to learn certain things outside the system is well placed and educators should encourage and support students in finding these opportunities.

Finally, a greater engagement with the community, with children, the disadvantaged etc. is good advice and university programmes may well strive to offer placements in the form that Jonathan suggested. This can serve two purposes: a) help students 
realise what community values are and to learn to listen and 'interact', but it may also b) help communities to complete projects to improve their environment with the help of the students' services. Some US universities have pioneered such 'service learning' as part of their third mission (besides research and teaching). These community engagements are not easy - they require long term commitments to build trust and often special arrangements in terms of pedagogy and administration. How do students get credit for such work? How can it be assessed fairly? How can the department ensure that students produce the goods the community requires? How are quality standards controlled, etc. Nonetheless, if programmes work, there is much benefit for all sides involved (see for example Kotval, 2003; Dewar and Isaac, 1998).

History tells us that it is not just in a market economy good advice to listen to clients and customers. In this case - we asked the students and now it is up to us to listen, evaluate and act. Considering the tendencies towards student-centred learning by which students define their own learning pathways and strategies in conjunction with some of the best learning experiences identified by students above - there is, I believe an opportunity to rethink our educational offerings. To allow some of the wealth of experiences to blossom, we may need more flexible curricula that are not overburdened with core requirements, leaving students the choice between perfecting their computer aided drafting, or traditional drawing techniques, between a community placement, or practical skills sessions on campus. These broader and more flexible curricula will also provide staff with greater opportunity to teach about their research and specialities which will likely increase their enthusiasm. We also need to find ways of engaging with students which do not stifle their curiosity and motivation to experiment and explore. This may require us to give up control and have more patience, but students' learning experiences and our teaching experiences may change for the better in doing so, over the long run.

\section{References}

Bayer, H. (1975). Bauhaus 1919-1928. New York: The Museum of Modern Art.

D'Anjou, Philippe (2004) Theoretical and methodological elements for integrating ethics as a foundation into the education of professional and design disciplines. Science and Engineering Ethics, 10(2), 211-218.

Dewar, Margaret E., and Isaac, Claudia B. (1998) Learning from difference: The potentially transforming experience of community-university collaboration. Journal of Planning Education and Research, 17(4), 334-347.

Forester, John (2004) Reflections on trying to teach planning theory. Planning Theory \& Practice, 5(2), 242-251.

Frank, Nancy (2002) Rethinking planning theory for a master's level curriculum. Journal of Planning Education and Research, 21(3), 320-330. 
Kaufman, Jerome L. (1993) Reflections on teaching three versions of a planning ethics course. Journal of Planning Education and Research, 12(2), 107-115.

Kotval, Zenia (2003) Teaching experiential learning in the urban planning curriculum. Journal of Geography in Higher Education, 27(3), 297-308.

Lynch, K., Barnden, A., Carbone A., and Gonsalvez, C. (2002) Are we there yet? IT graduates - Bauhaus style. [online] Available from http://www.ascilite.org.au/conferences/auckland02/proceedings/papers/133.pdf [accessed 20 November 2005]

\section{Note}

The five finalist student essays from the CEBE Student Essay Competion 2004-05 are reproduced in full on the CEBE webpages:

http://www.cebe.heacademy.ac.uk/news/events/competition/award2004.php 